\title{
Ensino e Investigação do Conceito de Erosão no Ensino Fundamental em uma Abordagem Histórico-Cultural do Processo da Formação de Conceitos
}

\section{The Teaching and Investigation of the Concept of Erosion in Elementary School from a Historical-Cultural Approach to the Process of Concept Formation}

Barbara Rodrigues Layoun ${ }^{1}$

Angela Maria Zanon' 1Universidade Federal de Mato Grosso do Sul (UFMS), Instituto de Física, Campo Grande, MS, Brasil.
Autora correspondente: barbararlrodrigues@gmail.com

Resumo: A investigação sobre a formação do conceito de erosão foi objeto de uma pesquisa realizada com alunos do $6^{\circ}$ ano do Ensino Fundamental em uma Escola Pública Municipal de Campo Grande, Mato Grosso do Sul (MS). As etapas de ensino privilegiaram atividades de aprendizagem com a problematização dos processos erosivos de um bairro e da escola, sendo que a horta escolar foi utilizada para proporcionar a reflexão acerca da dinâmica do solo, buscando uma solução para os problemas estudados com os alunos. A investigação revelou o processo dinâmico da formação conceitual durante a sequência didática que se apresenta neste artigo, com elementos do pensamento dos alunos durante os diálogos e atividades que desenvolveram no processo. A relação dos alunos com o ambiente e a utilização do espaço da escola como aspecto ativo no processo educativo evidenciaram a influência do meio social para a formação de conceitos.

Palavras-chave: Conceito científico; Manejo ecológico; Ensino de geografia; Ensino fundamental; Sequência didática.

Abstract: The investigation on the formation of the concept of erosion was the object of a research conducted with students of the $6^{\text {th }}$ year of Elementary School in a Municipal Public School of Campo Grande, Mato Grosso do Sul (MS). The teaching stages privileged learning activities with the problematization of the erosive processes in a neighborhood and the school, and the school garden was used to provide reflection on soil dynamics in order to seek a solution to the problems studied with the students. The investigation revealed the dynamic process of concept formation during the educational sequence presented in this article, with elements of the students' thinking during the dialogues and activities they developed in the process. The students' relationship with the environment and the use of the school space as an active aspect in the educational process showed the influence of the social environment on the formation of concepts.

Keywords: Scientific concept; Ecological management; Geography teaching; Primary education; Didactic sequence.

Recebido em: 16/08/2018

Aprovado em: 15/09/2019 


\section{Introdução}

O ensino de conceitos científicos nas escolas tem sido influenciado por diversas correntes teóricas, gerando muitas transformações e debates que visam romper com o ensino denominado tradicional.

Embora as abordagens ou metodologias sejam de escolha das instituições, sistemas ou redes de ensino no âmbito dos currículos e dos projetos pedagógicos, considerando cada realidade, contexto e características dos alunos (BRASIL, 2018), a metodologia escolhida influi no resultado do processo de ensino-aprendizagem. Metodologias diferentes podem ser eficientes de acordo com os objetivos pretendidos pelo professor (CAMPOS; NIGRO, 2009).

Para o Ensino de Geografia, a capacidade de compreensão da realidade deve ser desenvolvida a partir da sua espacialidade, pois os objetos dos conhecimentos na escola referem-se ao espaço geográfico, que é resultante das ações vividas pelas pessoas (CAVALCANTI, 1998). "Orientar o ensino para essa direção requer um olhar atento para a geografia cotidiana dos alunos, com a dimensão da geografia científica, do espaço concebido por essa ciência, que se tem a possibilidade de reelaboração e maior compreensão do vivido." (CAVALCANTI, 2008, p. 141-142).

Estudar a realidade pressupõe o estudo do espaço vivido pelos sujeitos do processo da construção do conhecimento, espaço que é objeto de estudo da Geografia e de várias outras áreas do conhecimento, mas sob óticas diferentes e de onde também surgirão os conceitos cotidianos e científicos que se relacionam a esta realidade.

Quando os conceitos são problematizados a partir da realidade vivida pelos alunos, a formação dos conceitos científicos direciona para a trajetória de seu processo de formação, uma vez que não pode ocorrer somente em sala de aula. Assim, o espaço geográfico assume um aspecto ativo no processo educativo.

Os temas transversais que emergem da realidade vivida devem estar inseridos no currículo sob o viés da interdisciplinaridade. A Educação Ambiental, entendida como uma educação "[...] em que cada sujeito aprende com conhecimentos científicos e com o reconhecimento dos saberes tradicionais, possibilitando a tomada de decisões transformadoras, a partir do meio ambiente natural ou construído no qual as pessoas se integram" (BRASIL, 2013, p. 515), deve estar inserida em todos os níveis da educação escolar, objetivando a construção de conhecimentos e o desenvolvimento de valores.

Com base nestes pressupostos, o conceito de erosão foi objeto de investigação em uma Escola Pública Municipal do município de Campo Grande, estado de Mato Grosso do Sul (MS), por estar presente no contexto da escola e em um bairro localizado nas proximidades. A partir da realidade vivida, foi realizada uma intervenção pedagógica fundamentada na Teoria Histórico-Cultural e concepções de Vigotski (2009) para estudar a formação de conceitos. A proposta foi investigar a formação do conceito de erosão por parte dos alunos de $6^{\circ}$ ano do Ensino Fundamental. O espaço da escola foi utilizado para a construção de uma horta que fez parte do processo da formação desses conceitos. A pesquisa atendeu aos requisitos éticos estabelecidos para a pesquisa científica.

O objetivo deste artigo é apresentar elementos do pensamento de alunos do $6^{\circ}$ ano do Ensino Fundamental no processo da construção do conceito de erosão diante de uma situação de ensino e investigação, fundamentada na Teoria Histórico-Cultural. 


\section{O Processo da Formação de Conceitos para Vigotski}

A Teoria Histórico-Cultural tem suas raízes na psicologia e seus fundamentos principais nas concepções de Lev Semenovich Vigotski (1896-1934). A teoria, que está baseada no materialismo histórico-dialético, abrange dois conceitos articuladores no desenvolvimento humano: o contexto histórico, uma vez que o sujeito constitui-se historicamente; e o contexto cultural, pois se transforma nas relações sociais.

Vigotski considerou que o desenvolvimento das funções psicológicas complexas, desde a infância, possui natureza mediadora, assim como os meios pelos quais a sociedade organiza as tarefas que as crianças realizam e os instrumentos que utilizam para resolver as referidas tarefas são socialmente estruturados. "Os instrumentos que o homem usa para dominar seu ambiente e seu próprio comportamento [...] foram inventados e aperfeiçoados ao longo da história social do homem" (LURIA, 2016, p. 26). Por isso, deu ênfase à linguagem, fundamental na organização e desenvolvimento dos processos de pensamento e que "[...] carrega consigo os conceitos generalizados, que são a fonte do conhecimento humano." (LURIA, 2016, p. 26).

Vigotski criticou os métodos de sua época que sustentavam a pesquisa da psicologia, uma vez que os objetivos eram focados nos dados quantitativos e analisavam o ser humano de forma fragmentada e descritiva, separando, por exemplo, o desenvolvimento biológico do cultural. Para o autor, o sujeito constitui-se nas relações histórico-culturais e o objeto estudado tem relação dialética com o próprio sujeito. Portanto, propôs um método que levasse em consideração o processo e análise explicativa da relação dialética entre o objeto estudado e a realidade que o compõe histórica e culturalmente.

Vigotski denominou seu método de genético-experimental, pois analisou que uma pesquisa deve abranger o processo de desenvolvimento, desde quando se inicia até o fim, estudando as fases de mudanças. Conforme o autor, "[...] estudar alguma coisa historicamente significa estudá-la no processo de mudança: esse é o requisito básico do método dialético." (VIGOTSKI, 2007, p. 68).

Segundo González (2012), a reciprocidade entre o objeto e o sujeito para a investigação indica considerar sua totalidade para buscar a origem de um problema. "O método históricodialético não nos permite pensar nem agir dicotomicamente, porque esse método tem uma ação abrangente, totalizante e só analisa o processo dos fatos, não o resultado final do processo. [...] o processo indica a forma qualitativa da pesquisa." (GONZÁLEZ, 2012, p. 102103).

Da mesma maneira que investigou os processos psicológicos, Vigotski deu atenção para a investigação da formação dos conceitos, vistos como um processo, pelo qual a criança passa por vários estágios de desenvolvimento até o uso da palavra de forma generalizada.

A formação dos conceitos inicia-se nas primeiras fases da infância, abrange vários estágios, forma-se e desenvolve-se durante a puberdade. "A formação de conceitos ou a aquisição de sentido através da palavra é o resultado de uma atividade intensa e complexa (operação com palavra e signo), da qual todas as funções intelectuais básicas participam em uma combinação geral." (VIGOTSKI, 2009, p. 168). Esse processo opera-se em três estágios básicos, que podem ser subdivididos em fases. 
No estágio em que as crianças ainda são pequenas, o significado das palavras pode ser considerado "um encadeamento sincrético não enformado de objetos particulares", que coincidem com os significados dos adultos para os mesmos objetos concretos, permitindo, assim, o entendimento. Esse estágio ainda pode ser subdividido em três fases distintas (VIGOTSKI, 2009, p. 175).

A primeira fase no modo de pensamento seria a de aproximações sucessivas, por tentativas e erros, de modo que os agrupamentos são formados ao acaso. Essa fase seguese pelo agrupamento determinado pela posição espacial dos objetos e do campo visual da criança, em que produz uma ordem dos objetos todos reunidos. Na terceira fase, os agrupamentos são compostos por elementos retirados dos grupos sem relação entre si.

No segundo estágio, denominado de "pensamento por complexos", os objetos individuais isolados encontram-se reunidos no pensamento da criança por suas impressões subjetivas e por relações existentes entre esses objetos. Nesse nível, a criança superou parte do egocentrismo. "O pensamento por complexos já constitui um pensamento coerente e objetivo. [...] O complexo se baseia em vínculos fatuais que se revelam na experiência imediata." (VIGOTSKI, 2009, p. 178; 180). Esse estágio subdivide-se em cinco fases.

A primeira fase é o complexo associativo, quando o grupo é formado por objetos que possuem uma semelhança, um contraste ou proximidade no espaço. A palavra deixa de ter o nome próprio do objeto e passa a ser o nome do grupo de objetos. A fase seguinte é os complexos-coleções, com características de agrupamentos feitos pela criança, que são baseados em sua participação na mesma operação prática. A fase do complexo em cadeia ocorre quando o significado é transmitido de um elo a outro e os objetos são agrupados, havendo uma percepção mais concreta. Mas é um agrupamento de elementos isolados sem um elemento que os interliga.

O quarto tipo é o complexo difuso, quando os agrupamentos são feitos por uma pequena semelhança ou a uma vaga impressão de que têm algo em comum. As conexões são difusas e indeterminadas. Já o quinto complexo é o pseudoconceito, nessa fase, ocorre uma forma de generalização, quando os agrupamentos ocorrem pela semelhança concreta visível, formando apenas um complexo associativo, restrito a um determinado tipo de conexão perceptual.

Para formar um conceito, é necessário que o indivíduo abstraia e isole os elementos, examinando-os em nível abstrato, separadamente da totalidade da experiência concreta. Portanto, o terceiro estágio do processo de formação de conceitos refere-se ao desenvolvimento da abstração, que se subdivide em três fases.

Na primeira fase ocorre um processo da abstração quando o agrupamento de objetos por semelhanças é superado pelo agrupamento em uma única característica, sendo também transitória para os conceitos. Para Vigotski, o conceito em sua forma natural e desenvolvida

[...] pressupõe não só a combinação e a generalização de determinados elementos concretos da experiência mas também a discriminação, a abstração e o isolamento de determinados elementos e, ainda, a habilidade de examinar esses elementos discriminados e abstraídos fora do vínculo concreto e fatual em que são dados na experiência. (VIGOTSKI, 2009, p. 220).

Dentre a relação de conceitos, há a fase dos conceitos potenciais, formados a partir da ação e do comportamento dirigido pela percepção, na semelhança de significados. Neste caso, a palavra é utilizada para orientar todos os processos parciais da fase superior da gênese dos conceitos. 
"O conceito surge quando uma série de atributos abstraídos torna a sintetizar-se, e quando a síntese abstrata assim obtida se torna forma basilar de pensamento com o qual a criança percebe e toma conhecimento da realidade que a cerca." (VIGOTSKI, 2009, p. 226). Assim, a formação do conceito pressupõe o uso da palavra deliberadamente empregada para dirigir todos os processos psíquicos e simboliza o conceito por meio de um signo.

É com o uso da palavra que "[...] a criança orienta arbitrariamente a sua atenção para determinados atributos, com a palavra ela os sintetiza, simboliza o conceito abstrato e opera com ele como lei suprema entre todas aquelas criadas pelo pensamento humano." (VIGOTSKI, 2009, p. 226). O significado da palavra é um fenômeno tanto do pensamento quanto da linguagem, constatado pelo fato de o significado da palavra ser uma generalização e, portanto, um ato verbal do pensamento, por isso o significado da palavra é uma parte intransferível dela (MOLON, 2016).

Para estudar a formação dos conceitos acompanhando seu processo, de sua gênese ao seu desenvolvimento, Vigotski baseou-se em um método que fornece os indícios do processo dinâmico da formação conceitual, sendo possível acompanhar todas as suas fases. Um problema é apresentado no início da experiência e permanece o mesmo até o final, sendo, portanto, indispensáveis para o surgimento de todo o processo da formação conceitual: a colocação do problema e o surgimento do objeto. Mas os meios para sua solução irão sendo introduzidos gradualmente a cada tentativa do sujeito para a solução do problema. (VIGOTSKI, 2009).

A formação dos conceitos tem início com um problema, e para que sua solução seja possível, faz-se necessária a formação de novos conceitos. Exige também o desenvolvimento de funções psicológicas complexas. Neste processo dinâmico, são fornecidos subsídios para que o sujeito forme os conceitos, sendo aprofundados gradualmente, uma vez que sua formação é um processo.

As evidências que os conceitos são formados ocorrem quando o sujeito utiliza os novos conceitos ao falar sobre outros objetos diferentes dos experimentos, definindo o seu significado de uma forma generalizada, significando que ele transferiu os conceitos para outros objetos (VIGOTSKI, 2008, 2009). Com o avanço da adolescência torna-se mais frequente o uso dos verdadeiros conceitos.

No entanto, como explicou Vigotski (2009, p. 171), o meio social circundante motiva e leva o adolescente a avançar no desenvolvimento de seu pensamento "[...] com o auxílio dos problemas propostos, da necessidade que surge e é estimulada, dos objetivos colocados perante o adolescente". Assim, o pensamento do adolescente pode desenvolver suas potencialidades onde o meio social cria problemas correspondentes, apresenta novas exigências, motiva e estimula com novos objetivos. Considera-se, portanto, relevante que o processo da formação de conceitos tenha início com um problema que desencadeie a formação de novos conceitos.

Vigotski (2009) considerou ainda a formação dos conceitos científicos na idade escolar, devido à sistematização das tarefas que as crianças realizam na escola e sua respectiva contribuição na formação dos conceitos científicos. Com base em suas pesquisas, afirmou que "[...] o desenvolvimento dos conceitos científicos - autênticos, indiscutíveis, verdadeiros - não podem deixar de revelar no processo investigatório as leis mais profundas e essenciais de qualquer processo de formação de conceitos em geral." (VIGOTSKI, 2009, p. 242). 
Neste contexto, o autor analisou os conceitos científicos e os conceitos espontâneos das crianças, também denominados de conceitos cotidianos. O desenvolvimento da gênese do conceito científico é afetado por condições externas e internas variáveis, que fazem parte tanto os conceitos cotidianos, adquiridos na vivência diária a partir de referentes concretos, quanto por conceitos não cotidianos, formados por meio do ensino.

Quando o aluno resolve o problema organizado pelo professor, em colaboração com outros colegas e, ao final, utiliza o conceito de maneira generalizada, transferindo seu significado para outros objetos que não aqueles estudados, esse processo revela vários indícios da trajetória da formação dos novos conceitos. Assim sendo, o ensino deve ser organizado pelo professor visando à formação de conceitos científicos.

\section{O Ensino e a Investigação da Formação do Conceito de Erosão}

O conceito de erosão foi objeto da investigação de uma pesquisa em uma Escola Pública Municipal em Campo Grande (MS), com alunos de duas turmas do $6^{\circ}$ ano do Ensino Fundamental, totalizando 54 participantes da pesquisa.

O conceito investigado foi escolhido por estar presente no contexto da escola e em seu entorno, pois a escola apresentava um processo erosivo em parte de seu limite interno, ocorrendo deslizamento de solo em períodos de chuva. Em um dos bairros do município, localizado na região urbana, circunvizinha à escola, onde muitos alunos residem, fortes chuvas aceleraram a erosão, afetando uma das ruas principais do bairro. Esse evento foi relacionado ao processo erosivo na escola.

Assinala-se que a investigação da pesquisa e a metodologia de intervenção pedagógica do conceito fundamentaram-se na perspectiva histórico-cultural para acompanhar o processo da formação conceitual.

A pesquisa esteve pautada na perspectiva teórico-metodológica vigotskiana e na análise microgenética para a produção dos dados, investigação e interpretação da formação dos conceitos científicos.

A análise microgenética é orientada para os detalhes indiciais, resultando na necessidade de recortes em um período que tende a ser restrito e, portanto, é considerada micro. Seu aspecto genético refere-se ao sentido "[...] de ser histórica, por focalizar o movimento durante processos e relacionar condições passadas e presentes, tentando explorar aquilo que, no presente, está impregnado de projeção futura" e, também, como sociogenética, "[...] por buscar relacionar os eventos singulares com outros planos da cultura, das práticas sociais, dos discursos circulantes, das esferas institucionais." (GÓES, 2000, p. 15).

A videografia associada à análise microgenética apresenta-se como uma ferramenta fundamental para a investigação, fornecendo indícios dos processos, que podem ser analisados com detalhes. Para a análise dos dados, seguiram-se os passos de Meira (1994) para a elaboração do índice de episódios. A partir do índice de dez episódios, os recortes dos eventos foram transcritos, tendo sido também geradas as interpretações dos microprocessos com base no referencial teórico adotado.

A sequência de atividades do projeto teve início com a problematização inicial do tema erosão, que se deu com a apresentação do processo erosivo no bairro, visando a identificação de conceitos prévios e contextualização do conceito de erosão, seguida da aula de campo, quando os alunos conheceram o local. A problematização teve continuidade no contexto da escola, quando identificaram o processo erosivo que ocorria em seus limites internos. 
Para a compreensão dos alunos sobre o processo erosivo e os conceitos relacionados a eles, pensou-se na construção de uma horta na escola para que conhecessem a dinâmica do solo e como seu manejo pode interferir nesse processo, a fim de conservar o solo ou gerar erosão. O objetivo de utilizar a estratégia da horta foi proporcionar um ambiente de aprendizagem para os alunos, de modo a observarem concretamente a dinâmica do solo em um canteiro com proteção de grama seca e outro canteiro sem a proteção, sendo este último, consequentemente, mais impactado pela água da chuva e da irrigação, ocorrendo deslizamento do solo. Assim, as atividades seguiram com a construção da horta na escola, oportunizando a reflexão e o estudo de uma solução para o processo erosivo com a prática do manejo ecológico e o conhecimento da ação dos microrganismos no processo da decomposição da matéria orgânica. O manejo da horta seguiu os princípios da Agroecologia (PRIMAVESI, 2006).

Os alunos socializaram os resultados do projeto, degustaram a rúcula que colheram e as atividades foram finalizadas com um novo plantio na horta da escola, como uma ação para minimizar o processo erosivo.

A sequência didática realizada com os alunos, tanto para o ensino como para a investigação, tiveram etapas para a verificação da transferência dos conceitos que estavam sendo formados para outras situações, diferentes das estudadas, como, por exemplo, a relação do estudo na horta com o estudo da solução para o processo erosivo.

A sequência didática utilizada ocorreu durante as aulas de Geografia e teve duração aproximada de 14 aulas. A Professora/Pesquisadora que conduziu o processo de ensino e investigação desempenhou uma relação de menor intervenção no ambiente investigado por fazer parte do corpo docente da escola, sendo o problema de pesquisa desencadeado a partir de sua vivência e reflexão no espaço escolar.

As atividades foram organizadas com a premissa de oportunizar a interação entre professor-aluno, aluno-aluno e aluno-aluno-professor, partindo do pressuposto que o aluno, o professor e os colegas são participantes ativos no processo educativo.

\section{Resultados da Investigação do Ensino do Conceito de Erosão}

O ensino do conceito de erosão foi organizado em uma sequência didática, que possibilitou a análise do processo. Teve início com um problema que só poderia ser resolvido com a formação de novos conceitos, como considerou Vigotski (2009).

O processo da formação de conceitos foi iniciado com a problematização do processo erosivo no Bairro. Para Vigotski (2008), quando os sujeitos são confrontados com um problema, utilizam os conceitos que já possuem para tentar resolvê-lo. Assim sendo, é viável identificar também o nível de desenvolvimento dos conceitos científicos, sendo possível acompanhar todo o processo de formação dos conceitos, desde o início.

Os resultados apresentados a seguir estão articulados às etapas desenvolvidas durante a sequência didática e respectiva análise interpretativa dos dados. Além dos vídeos e gravações, foram analisados os cadernos de campo, utilizados pelos alunos e as atividades escritas, desenvolvidas durante as aulas, que possuíam questões para a investigação da formação conceitual. Para o ensino e a investigação do conceito de erosão, foram desenvolvidas duas atividades. 
A primeira atividade, denominada Problematização do tema erosão no solo, foi organizada para a problematização do tema erosão no contexto do bairro, tendo sido separada em duas fases. A fase inicial teve como objetivo apresentar o processo erosivo no solo e identificar os conceitos prévios dos alunos quando confrontados com o problema. $\mathrm{O}$ problema proposto aos alunos, nesta fase, foi a descoberta das causas do processo erosivo. A segunda fase da atividade de problematização foi realizada com uma aula de campo no bairro e teve como objetivo oportunizar o conhecimento do processo erosivo no local de ocorrência, bem como levantar informações da causa, consequência e soluções para a erosão sendo, dessa forma, uma etapa importante para a formação de novos conceitos.

A segunda atividade, denominada Reflexão do processo erosivo, teve como objetivo oportunizar a pesquisa sobre a erosão que ocorreu no ambiente da escola. Os alunos foram confrontados com o seguinte problema: encontrar uma solução para o processo erosivo. Essa atividade ocorreu com as fases de construção da horta e a apresentação da ação dos microrganismos na decomposição da matéria orgânica. A horta foi construída com dois canteiros diferentes, onde foi possível a comparação do manejo e a reflexão sobre a influência das plantas e da cobertura vegetal para a estrutura do solo.

Além dos conceitos que os alunos possuíam no início do projeto, já havia ocorrido uma intervenção pedagógica nas aulas de Geografia com vários temas, entre eles: elementos da paisagem, espaço geográfico, elementos cartográficos, orientação, agentes internos e externos do relevo.

Para identificar os conceitos prévios dos alunos foram apresentadas imagens de satélite e fotos da erosão do bairro. Quando solicitados a identificarem os elementos presentes nas imagens, os alunos apontaram: árvores, casas, a avenida, e buracos, sendo o último termo utilizado pelos alunos como um conceito espontâneo. Em seguida, foram apresentados vídeos de reportagens sobre o local, que traziam algumas soluções para o problema, também sendo direcionadas perguntas para identificar os conceitos já formados pelos alunos para a solução do problema apresentado nesta etapa.

Os diálogos apresentados a seguir são trechos dos episódios, enumerados para a melhor apresentação neste artigo, observa-se que a identidade dos sujeitos da pesquisa foi preservada, substituídos os nomes por letras e números. Em momentos de interação entre os alunos, quando a participação é intensa e ocorrem falas justapostas, não foi possível identificar a que alunos pertenciam essas falas e, por isso, são a presentadas sem identificação. Ressalta-se que as atividades escritas e orais possuem muitos erros de grafia e concordância, de modo que, a título de melhor compreensão para o leitor, foram adequadas conforme as regras vigentes da Língua Portuguesa.

1. Professora/pesquisadora: Porque será que eles não construíram nesta área aqui?

2. S1: Porque tem um buraco?

3. Professora/pesquisadora: O que será que está acontecendo neste local, para chegar a este ponto? [referindo-se à imagem da erosão no bairro].

4. M2: Por causa da água, a água entrou debaixo e blem. [fez movimento de uma explosão].

5. Professora/pesquisadora: $E$ aí, vocês acham que se tampar ali vai resolver o problema? [referindo-se à solução da prefeitura em tampar o local com entulho, a qual foi apresentada no vídeo de reportagem].

6. M2: Pode chover e pode abrir tudo de novo.

7. DD2: Professora, aquela é a nascente? 
Nos diálogos, é possível observar os conceitos cotidianos dos alunos, quando eles utilizam a palavra buraco na fala (2) de S1, ao visualizarem as imagens da erosão.

Ao serem confrontados com o problema, pode-se notar que a solução que os alunos apresentam carece de conceitos científicos e está ligada a seus conceitos cotidianos como apresentado na fala (6) de M2. Além disso, aparecem os conceitos que possuem sobre a causa do problema proposto, evidenciado na fala (4), considerando a água da chuva como a causa do problema. A fala (7) do aluno DD2 traz influência da aula e de um dos vídeos apresentados, que faz referência à presença de nascentes no local.

Vigotski analisou que o desenvolvimento dos conceitos espontâneos e científicos é um processo interligado que exerce influências um sobre o outro. $O$ desenvolvimento dos conceitos científicos apoia-se em um "[...] determinado nível de maturação dos conceitos espontâneos" e os conceitos científicos, por sua vez, influenciam "[...] o nível dos conceitos espontâneos anteriormente constituídos." Portanto, trata-se de "[...] um único processo de formação de conceitos, que se realiza sob diferentes condições internas e externas mas continua indiviso por sua natureza [...]." (VIGOTSKI, 2009, p. 261).

Os conceitos espontâneos distinguem-se dos científicos por sua relação com a experiência pessoal da criança, como o conceito de buraco, por exemplo. Para resolver a atividade e o problema apresentados aos alunos, quanto a descobrirem a causa do processo erosivo no bairro, muitos conceitos são necessários. Aos poucos, esses conceitos vão sendo introduzidos como meios mediados para a formação do conceito principal: o conceito de erosão.

Nas soluções apresentadas pelos alunos, surgem elementos do estágio denominado pensamento por complexos, na trajetória para a formação dos conceitos. Essa fase pode ocorrer muitas vezes no início da formação de novos conceitos, sendo que os seus indícios apareceram quando os alunos, solicitados a responderem ao problema, associam os objetos por uma semelhança, um contraste ou ainda uma proximidade no espaço. "A principal função dos complexos é estabelecer elos e relações." (VIGOTSKI, 2008, p. 95). Qualquer relação entre o objeto e aquilo que já conhecem também pode aparecer como resposta, pois, diferentemente dos conceitos, no complexo, os objetos estão generalizados pelos fundamentos factuais diversos. "A diversidade de vínculos, que servem de base ao complexo, constitui o seu traço mais importante que o difere do conceito, caracterizado pela uniformidade dos vínculos que Ihe servem de base." (VIGOTSKI, 2009, p. 181). Esse estágio conceitual pode ser evidenciado, por exemplo, quando o aluno M2, na fala (4), utiliza a expressão blem e os gestos, como se a área estivesse aberta a partir de uma explosão.

A segunda fase da atividade de problematização foi realizada com a visita ao bairro e informações sobre a ocorrência da erosão no local. Nessa fase, a professora/pesquisadora faz o uso da palavra erosão correta e deliberadamente, explica o ciclo da água e os agentes erosivos, bem como suas causas naturais e antrópicas. Observa-se que não foi fornecida a resposta pronta, pois mesmo com a explicação dos agentes erosivos, a construção conceitual foi sendo desenvolvida passo a passo, para acompanhar o processo dinâmico da formação dos conceitos. Dessa maneira, a relação entre as etapas das aulas e as soluções dos problemas propostos ocorreria por parte dos alunos.

$\mathrm{Na}$ aula de campo, quando visitaram o local da erosão no bairro, os alunos fazem registros com a descrição da paisagem, do solo, da vegetação e de entrevistas com os moradores. Essa foi uma fase importante da sequência didática por fornecer informações ao problema que deveriam resolver: pesquisarem a causa e a solução do processo erosivo. 
8. Professora/pesquisadora: Ela falou [citando a entrevista] que, antes do asfalto, quando ela mudou para cá, há sete anos, aqui tinha muitas árvores, e depois as árvores foram caindo.

9. AA1: Normalmente, por causa da erosão.

10. J1: Normalmente, não... [não completa a frase].

11. Professora/pesquisadora: Então, porque será que começaram a cair essas árvores?

12. Por causa do buraco?

13. AA1: Por causa da erosão.

14. Por causa do lençol freático.

15. J1: Porque o solo foi cedendo?

16. Por causa da nascente.

Diante dos questionamentos, os alunos procuram solucionar as questões que são colocadas e, para isso, utilizam elementos variados da aula de campo. As falas dos alunos, pela relação de suas respostas a partir da memória da aula, assemelham-se aos complexos difusos na formação conceitual, com conexões difusas e indeterminadas (VIGOTSKI, 2008).

A formação do conceito de erosão, e de seu processo no bairro, teve continuidade no retorno à escola. Várias informações fornecidas nas entrevistas continham subsídios para a conclusão que a ocupação urbana do local em uma área de nascentes contribuiu para alterar o escoamento natural das águas das chuvas e acelerar o processo de erosão do solo. Para essa conclusão, os conceitos do ciclo da água e as bacias hidrográficas seriam os conceitos mediadores, para que os alunos chegassem a uma possível solução de um dos problemas propostos a eles: descobrir a causa da erosão no local. Mas, pelos registros dos alunos, observou-se que alguns desses conceitos não haviam sido formados, o que pode interferir no processo de formação conceitual.

Portanto, considera-se relevante que o professor organize o ensino, levando em conta os conceitos mediadores e o sistema hierárquico de inter-relações desses conceitos, pois, como ponderou Vigotski, os conceitos científicos "[...] mediados por outros conceitos - com seu sistema hierárquico interior de inter-relações -, são o campo em que a tomada de consciência dos conceitos, ou melhor, a sua generalização e a sua apreensão parecem surgir antes de qualquer coisa." (VIGOTSKI, 2009, p. 290). Assim sendo, pode-se pensar em um currículo que vise à continuidade do processo da formação conceitual em séries subsequentes que oportunize as inter-relações dos conceitos.

Além dos diálogos, os registros dos alunos no caderno de campo, que os acompanhou em todo o projeto, trouxeram mais evidências dos conceitos cotidianos, dos conceitos formados e a influência das aulas no processo de formação conceitual.

DD2: Hoje na aula de campo aprendi que as nascentes nascem em lugares altos para descer para o rio para ser brotadas e mandadas para nossas casas. E que as águas de baixo da terra são sugadas pelas raízes das árvores.

R1: No bairro Nova Lima a situação é crítica pela erosão e se tiver mais um longo tempo de chuvas é muito provável que comece a aumentar a erosão. A moradora falou que já ficou até sem luz por causa da cratera.

Z2: A erosão foi por causa da enchente das nascentes. É um solo vermelho e pedras e areia e gramas. Tinha um buracão.

Muitos alunos utilizam as palavras buraco e buracão na fala e na escrita. $O$ fato de utilizarem essas palavras evidencia que seu pensamento relaciona-se à segunda fase do pensamento por complexos, descrita por Vigotski (2008), como coleções, pois o conceito 
que os alunos possuem de buraco ou buracão parte de sua experiência direta e observação na experiência prática. Ao verem a voçoroca, eles observam sua participação na mesma operação prática do buraco que já conhecem e, portanto, agrupam a voçoroca e os buracos em um mesmo grupo de conceitos.

No entanto, ao utilizarem a palavra erosão, como nas falas (9) e (13) de AA1, e nos registros de DD2 e R1, não há evidência que já assimilaram seu conceito, pois, de acordo com Vigotski (2008), quando a criança aprende uma palavra nova, trata-se somente do início do desenvolvimento de seu significado. O significado da palavra evolui e é substituído por generalizações mais complexas à medida que o intelecto também se desenvolve.

Nos registros de R1 e de Z2, aparecem as palavras erosão, cratera e buracão, revelando que ainda agrupam os conceitos em um mesmo conjunto, podendo também ser considerado um complexo de coleções no processo da formação de conceitos.

Além de aparecer a palavra erosão, como influência das aulas, outras palavras relacionam-se aos conceitos cotidianos dos alunos, como a palavra sugada escrita por DD2, e a influência dos vídeos, como a palavra cratera utilizada por R1.

Os processos de formação dos conceitos científicos e dos conceitos espontâneos são opostos, mas estão internamente e profundamente inter-relacionados. "O desenvolvimento do conceito espontâneo da criança deve atingir um determinado nível para que a criança possa apreender o conceito científico e tomar consciência dele." (VIGOTSKI, 2009, p. 349). Assim sendo, entende-se como relevante que o professor analise também os conceitos espontâneos no processo da formação de novos conceitos científicos.

O registro de DD2 apresenta ideias que se relacionam ao ciclo da água, abordado na explicação anterior à aula de campo, que ocorreria na mesma semana, e esses elementos aparecem misturados na primeira parte de seu registro. Na segunda parte, quando escreve: "as nascentes nascem em lugares altos para descer para o rio" reporta-se ao percurso da formação do rio, mas DD2 mistura esse elemento com o seguinte "para ser brotados $e$ mandados para nossas casas". O segundo trecho refere-se à captação de água das nascentes para abastecimento das casas. O último trecho "e que as águas debaixo da terra são sugadas pelas raízes das árvores" diz respeito à formação do lençol freático e das águas subterrâneas. O registro de DD2 demonstra que o conceito do ciclo da água ainda não está completamente formado.

Apesar de o conceito de hidrografia estar presente no currículo de Geografia do $5^{\circ}$ ano e o ciclo da água, em Ciências para o $6^{\circ}$ ano, considerou-se relevante sua abordagem devido à inter-relação dos conceitos, contribuindo para a criação de novos vínculos conceituais no processo da formação do objeto investigado.

O registro de DD2 assemelha-se a um complexo do tipo em cadeia, pois os elementos isolados estão agrupados sem um elemento que os interliga. "O complexo em cadeia se constrói segundo o princípio da combinação dinâmica e temporal de determinados elos em uma cadeia única e da transmissão do significado através de elos isolados dessa cadeia" (VIGOTSKI, 2009, p. 185), e que caracteriza o pensamento por complexos que não opera por uma lógica abstrata, como o faz em um conceito. É relevante ressaltar que muitas vezes o texto que as crianças apresentam não possui lógica para os adultos, mas quando elas operam por complexos, as conexões que realizam a partir dos fatos concretos podem ser influenciadas por diferentes atributos, o que se reflete em seu texto (VIGOTSKI, 2008). Além disso, a diversidade de elementos que aparece nos registros e diálogos dos alunos da pesquisa demonstra a grande diferença entre os níveis de desenvolvimento. 
Para Vigotski, a formação do conceito deve ser seguida por sua transferência para outros objetos que não os que estão sendo estudados, com a utilização dos novos termos para falar de objetos diferentes dos experimentais e definir o seu significado de maneira generalizada. O autor definiu o processo de transferência de conceitos como sendo a aplicação da experiência da situação concreta

[...] a outros objetos inteiramente heterogêneos, quando os atributos discriminados mas sintetizados nos conceitos se encontram em outro ambiente de atributos concretos bem diferentes e quando estes mesmos são dados em outras proporções concretas. (VIGOTSKI, 2009, p. 230).

Sendo assim, para a realização do processo que foi denominado na pesquisa de verificação da formação conceitual, os sujeitos foram levados a utilizar os novos termos que estavam sendo formados, quando confrontados com o processo erosivo no contexto da escola. Até essa etapa não havia sido levantado, junto aos alunos, o conhecimento do problema dentro da escola. Contudo, ocorreram diferentes percepções dos alunos em relação ao ambiente escolar.

Ao visitarem o local em que ocorre o processo erosivo na escola, os alunos são confrontados com o problema e a verificação da formação dos conceitos é possível por meio da transferência que realizam dos conceitos formados no contexto do bairro para o contexto da escola. Durante as aulas e interação no espaço, foi possível observar se os alunos utilizavam a palavra erosão deliberadamente ao falar sobre o local.

Os alunos, a exemplo da aula de campo no bairro, são orientados a caracterizarem o local da escola, registrando no caderno de campo. A transferência foi observada e evidenciada quando os alunos caracterizaram o ambiente, nos diálogos durante a interação no espaço e registros no caderno de campo, como, por exemplo S1: "Bloco H perto da sala 28. Estamos na escola. Terra: arenosa e avermelhada. Eles tentaram plantar grama, mas não dá porque está morto e todo mundo pisa nela e não cresce, a chuva causou a erosão aqui."

Nessa etapa, é possível verificar o desenvolvimento conceitual de S1, pois, na fala (2), utilizava a palavra buraco e, na presente etapa, já utiliza a palavra erosão, resultado da intervenção pedagógica. Embora não relacione os elementos da aula de campo com o processo erosivo na escola quando afirma que "a chuva causou a erosão aqui".

No espaço do processo erosivo da escola, o aluno A2, com o gravador na mão, entrevista os colegas e é acompanhado por outro, que leva a câmera.

\section{A2: Quando você chegou aqui já tinha essa erosão?}

18. R2: Já. Essa erosão não é igual do Nova Lima, porque no Nova Lima começou com chuva.

A transferência dos conceitos e das atividades desenvolvidas pode ser evidenciada pelo uso da palavra erosão, nas falas (17) e (18), quando utilizam a palavra deliberadamente e a comparação que o aluno R2 faz com o bairro que visitaram apresentado na fala (18).

No entanto, o aluno R2 afirma que a causa da erosão do bairro foi a chuva, sem apresentar o que considera ser a causa do processo erosivo na escola, não revelando também outros elementos presentes nas aulas que explicassem as causas dos processos erosivos, diferentemente de $\mathrm{S} 1$. As respostas dos alunos revelam a fase de desenvolvimento conceitual evidenciada quando os alunos são confrontados com um novo problema, o que exigiu que utilizassem os conceitos que já estavam formados e também a formação de novos conceitos. 
Por isso, compreende-se a atividade de transferência de conceitos como uma importante etapa no processo de formação conceitual, fornecendo subsídios para a pesquisa e para o professor, podendo ser utilizada como uma forma mais efetiva de avaliação. Os diferentes níveis de desenvolvimento conceitual dos alunos revelam-se em um desafio ao professor em sala de aula, principalmente em uma escola pública, com turmas numerosas.

A comparação do registro de S1 e da fala de R2 demonstra elementos concretos e factuais, mas há também elementos da lógica de $\mathrm{S} 1$ ao fazer a relação entre a compactação do solo e a falta de vegetação, ao mesmo tempo que mistura os elementos quando afirma "tentaram plantar grama, mas não dá porque está morto". R2 também compara a erosão do bairro e da escola, embora não esclareça as causas que considera em seu pensamento.

Os diferentes elementos presentes no pensamento dos alunos traduzem as conexões que estão fazendo para formarem o novo conceito, além de evidenciar também, como afirmou Vigotski, que a transmissão de um conceito pelo professor ao aluno de forma simples e direta é impossível, pois um conceito "[...] é um ato real e complexo de pensamento que não pode ser aprendido por meio de simples memorização" (VIGOTSKI, 2009, p. 246).

A segunda atividade de Reflexão do processo erosivo ocorreu com a construção da horta, quando é apresentado um novo problema aos alunos: encontrar uma solução para o processo erosivo. Essa fase aconteceu com a formação de novos conceitos, como o manejo ecológico e a presença de microrganismos no solo, objetivando a formação do conceito de erosão, principal da pesquisa, seguida de atividades para verificar a sua transferência.

Os canteiros da horta foram preparados com manejo ecológico, utilizando compostos naturais de folhas e capim secos para preparar o solo. Um dos canteiros recebeu a proteção do solo com capim seco, a fim de diminuir o impacto da água da chuva e da irrigação. Foi realizado o plantio de rúcula, por ter um ciclo de vida curto, sendo possível o acompanhamento de todas as etapas, desde sua germinação à colheita, quando os alunos degustaram um lanche natural, com a hortaliça que colheram. Os alunos organizaram-se para regar a horta nos dias letivos e, nas aulas de Geografia, realizavam as anotações das observações dos efeitos da água comparando os dois canteiros.

Nas aulas de Geografia, algumas atividades possuíam questões direcionadas à investigação do processo da formação dos conceitos, ampliando a análise dos diálogos gravados. Quando questionados para explicarem como ocorre o processo de erosão no solo, os resultados direcionam para os elementos presentes nas etapas da sequência didática evidenciados nas respostas e também para os estágios do processo da formação dos conceitos.

AA2: Quando há queimadas, quando jogam lixo no solo e quando a chuva vem leva tudo.

B2: Se não tiver vegetação no solo, o processo de erosão fica mais fácil, quando chove, vai sair levando tudo que tiver na frente.

D1: O solo fica sem água e vai ficando muito arenoso e começa a erosão pouco a pouco.

E2: Por causa das chuvas.

F1: Quando chove, a água da chuva leva a areia do solo junto com ela, causando a erosão.

J1: Num lugar sem vegetação, a chuva cai no solo e, como estão sem vegetação, a chuva leva o solo, assim acontecendo a erosão.

J2: A água infiltra na terra até transbordar e, sem as árvores, a água não é sugada.

L1: Assim, tinha uma rua que não tinha asfalto, mas tinha as árvores, arrancaram as árvores e cimentaram, mas aí choveu e arrastou a areia para outro lado e a erosão foi crescendo. 
P1: Primeiro, as pessoas pisando e, depois, jogando lixos e, depois, a chuva e começa a ter erosão.

U2: Cortando as árvores, poluindo as matas e por causa da chuva, a chuva vai escorrendo e causando a erosão, o desmatamento vai abrindo uma cratera no solo e acontece a erosão.

Nessa etapa, a grande maioria da turma relaciona a ação da chuva e da água como geradores do processo de erosão e os elementos da queimada e o lixo como aparece em AA2, sem um elemento que os interligue, assim como a resposta de D1 que também apresenta elementos isolados dos conceitos. Esse processo assemelha-se a um complexo em cadeia no processo de formação dos conceitos (VIGOTSKI, 2008).

O registro de E2, a pesar de evidenciar que a erosão é causada por chuvas, essa conexão é indeterminada em sua resposta, não explicando o processo erosivo. Além da ação da chuva e a falta de vegetação, outros elementos aparecem como a compactação do solo citada por P1, evidenciando a influência da problematização no contexto da escola, quando o aluno afirma "primeiro as pessoas pisando". Em suas respostas, as conexões entre os elementos são indeterminadas, diluídas e, por isso, assemelham-se a um complexo difuso no processo de formação de conceitos. No complexo difuso, a combinação dos elementos tem "[...] como resultado um complexo que combina através dos vínculos difusos e indefinidos os grupos diretamente concretos de imagens ou objetos." (VIGOTSKI, 2009, p. 188).

A resposta de $\mathrm{J} 2$, apesar de explicar a importância da vegetação e aparecerem elementos das atividades na horta, não possui um elo com o processo de erosão e utiliza palavras de conceitos cotidianos, trazendo indícios de que ainda não se distanciou do concreto e factual, assemelhando-se a um pseudoconceito (VIGOTSKI, 2008).

O registro de L1 possui praticamente uma explicação possível de relacionar-se ao processo do bairro Nova Lima, quando cita o asfalto e o fato de cimentarem o local. Há indícios da relação dos elementos apresentados nas aulas, fazendo sua transferência para o contexto do bairro. No entanto, ainda não é possível identificar que o conceito foi completamente formado, pois sua resposta assemelha-se a um relato do que viu na aula de campo, além de possuir traços do concreto e factual, não demonstrando a relação que faz entre o asfalto, o desmatamento e a erosão. Por isso, seu pensamento ainda pode ser considerado como pseudoconceito (VIGOTSKI, 2008), uma forma de pensamento concreto, pois a combinação que faz dos objetos teve como base "[...] seus vínculos diretos fatuais e concretos, numa associação simples." (VIGOTSKI, 2009, p. 191). O pseudoconceito é um elo entre o conceito simbólico e concreto para o pensamento abstrato da criança.

A resposta de F1 relaciona somente a água da chuva como causa do processo de erosão, por isso, apesar de já possuir traços da abstração, não relaciona os outros elementos das aulas com o processo de erosão, o que demonstra indícios de que seu pensamento opera por conceitos de combinações máximas (VIGOTSKI, 2008).

Apesar de alguns alunos citarem a falta de vegetação do solo, não há evidências que a relacionem ao processo de erosão deliberadamente, pois, como se observa no registro de U2, os elementos chuva e desmatamento misturam-se, sendo possível identificar que não os relaciona. Desse modo, demonstra também a formação de conceitos por combinações máximas, sendo o primeiro passo à abstração (VIGOTSKI, 2008). 
$O$ registro de $B 2$ relaciona-se aos conceitos potenciais, visto que possui traços da abstração que não se perdem facilmente, observado em seus registros posteriores. "[...] a criança dessa fase de desenvolvimento costuma destacar um grupo de objetos que ela generaliza depois de reunidos segundo um atributo comum." (VIGOTSKI, 2009, p. 222). No registro de $\mathrm{J} 1$, também há indícios de conceitos potenciais, assim como do uso do pensamento lógico em sua frase. Sua abstração não se perde facilmente em outros elementos, e é o que se verificou em seus registros posteriores.

Muitos alunos, ao invés de explicarem como ocorre o processo erosivo, apresentavam suas causas. Isto acontece, pois, como analisou Vigotski (2008), as crianças começam a operar com proposições subordinadas antes de dominar totalmente as relações causais, condicionais ou temporais. $\mathrm{O}$ sujeito domina primeiramente a sintaxe da linguagem antes da sintaxe do pensamento, como é possível identificar na resposta de E2, o aluno ainda não domina completamente essas relações e sua resposta contém as causas, mas não o processo de erosão.

Assim, compreende-se que a avaliação da formação do conceito científico na escola não pode ser vista somente pela significação da palavra, pois, na trajetória de sua formação, aparecem muitos elementos que se apresentam ao professor indicando que o conceito está sendo formado. Esses elementos são importantes para avaliar a formação dos conceitos científicos enquanto configura-se como um processo influenciado por diferentes aspectos como já apontado.

A partir das respostas, verificou-se que, nessa fase, o desenvolvimento conceitual dos alunos, em relação ao processo da erosão, apresentava-se em níveis diferentes, sendo que apenas um terço do número de alunos, encontrava-se na fase de desenvolvimento da abstração, no processo da formação conceitual.

Esse resultado pode justificar-se, visto que toda a investigação de Vigotski (2009) concluiu que, somente com o avanço da adolescência, as formas de pensamento sincréticas e por complexos "[...] vão sendo gradualmente relegadas a segundo plano, o emprego dos conceitos potenciais vai sendo cada vez mais raro e se torna cada vez mais frequente o uso dos verdadeiros conceitos, que no início apareciam esporadicamente." (VIGOTSKI, 2009, p. 228).

Os conceitos científicos, para Vigotski (2008, p. 116), ocupam uma posição sistematizada em relação a outros, "dentro de um sistema de conceitos". Os conceitos científicos na escola e a relação da criança com algum objeto são sempre mediados por outro conceito. Para a formação de um novo conceito, como o conceito de erosão, seria necessário, por exemplo, que o conceito do ciclo da água já tivesse sido formado em etapas anteriores de desenvolvimento. A escola desempenha, portanto, uma importante tarefa quando inicia a criança no sistema de conceitos científicos (VIGOTSKI, 2009).

A Educação Ambiental permeou todas as etapas do projeto de forma interdisciplinar em uma perspectiva transformadora. "A Educação Ambiental Transformadora enfatiza a educação enquanto processo permanente, cotidiano e coletivo pelo qual agimos e refletimos, transformando a realidade de vida." (LOUREIRO, 2004, p. 81). A sequência didática priorizou atividades que permitissem a reflexão e a ação no ambiente da escola para transformar o processo erosivo que ali se encontrava. 
A horta, como ambiente organizado para a aprendizagem, gerou uma mudança de comportamento dos alunos em relação à conservação do solo, ao cuidado com o ambiente da escola e à percepção ambiental, reveladas nos diálogos e registros. No que tange às relações sociais com os colegas e o desenvolvimento da atenção deliberada, observou-se terem sido influenciados pelas atividades no ambiente da horta, que teve um papel ativo por promover situações reais, que os alunos, cotidianamente, não encontrariam na escola.

Como afirmou Vigotski (2010, p. 67), "[...] a educação se faz através da própria experiência do aluno, a qual é inteiramente determinada pelo meio, e nesse processo o papel do mestre consiste em organizar e regular o meio". A educação possui natureza social e o educador capaz de formar novas reações nos sujeitos é a própria experiência, o meio social estabelecido e educativo faz-se determinante para a elaboração do comportamento. Todas as coisas que se atribui um papel educativo tornam-se ativos no processo da educação e os professores devem organizar o meio para que se tornem educativos.

Com as atividades na horta, os alunos começaram a fazer a transferência da importância da vegetação para o solo, durante a observação dos canteiros, na ação de regar. Com a presença de vegetação e proteção do solo com as folhas secas somente em um dos canteiros, a água infiltrava no solo ao invés de levá-lo como acontecia anteriormente no espaço da escola.

O comportamento social dos alunos também foi se desenvolvendo principalmente no espaço da horta. As relações conflituosas entre os alunos e a divergência de interesses entre atividades práticas e teóricas foram sendo gradualmente transferidas para a aprendizagem de novos conceitos, com a intervenção da Professora/pesquisadora, da comunidade escolar como um todo e do próprio ambiente, quando em colaboração com os colegas para a solução de problemas encontrados no espaço da horta.

\section{Considerações Finais}

A investigação da formação do conceito de erosão evidenciou o processo dinâmico da formação conceitual e os elementos do movimento do pensamento dos alunos durante as atividades desenvolvidas. Nesse processo, devem ser considerados os conceitos espontâneos e os científicos como um único processo da formação de conceitos.

O professor também deve considerar os conceitos que estejam inter-relacionados ao conceito principal e aqueles que devam estar formados para que os novos conceitos possam desenvolver-se. No processo de formação do conceito de erosão, conceitos considerados mediadores, como o ciclo da água, por exemplo, deveriam ter sido desenvolvidos no ano escolar adequado em detrimento do processo da formação de novos conceitos, visto que a formação de conceitos é sempre mediada por outros já formados. Dentre as possibilidades de desenvolvimento dos conceitos que não haviam sido formados, foi utilizada, na pesquisa, a abordagem desses conceitos mediadores como parte do processo da formação do conceito de erosão, trazendo mais vínculos aos conceitos estudados. Muitas vezes, a explicação dos alunos carece de uma explicação científica, mas evidenciam elementos do processo da formação conceitual, o que deve ser ponderado pelo professor em sala de aula.

Para o Ensino de Geografia, os problemas vividos pela comunidade escolar, que estão presentes no espaço geográfico ao qual o aluno está inserido, foram relevantes para que os conceitos fossem formados sob essa perspectiva metodológica, ao mesmo tempo em que estavam sendo relacionados às questões globais. O ponto de partida deve ser um problema que possa ser resolvido com a formação de novos conceitos. 
A metodologia da horta com atividades práticas teve uma relevância para a formação conceitual devido ao processo de desenvolvimento dos alunos do $6^{\circ}$ ano do Ensino Fundamental. Nessa faixa de escolarização, os alunos necessitam de atividades concretas intercaladas com atividades abstratas, facilitando a transferência que fazem da realidade concreta à abstração. As atividades na horta e a visita ao bairro, por exemplo, trouxeram elementos concretos que foram necessários ao processo de formação conceitual sobre a erosão e motivaram os alunos a formar novos conceitos.

Os objetivos da pesquisa foram alcançados, revelados pelo desenvolvimento dos conceitos dos alunos durante a sequência didática desenvolvida. Portanto, a formação total do conceito de erosão e os demais conceitos não podem ser esperados nessa faixa etária escolar. Como ficou evidenciada na pesquisa, a formação de um conceito não ocorre com a simples explicação, sendo que sua generalização acontecerá na adolescência como considerado por Vigotski.

As limitações encontradas estiveram no número de alunos por turma, principalmente nas atividades desenvolvidas no espaço da horta. Por isso, acredita-se que turmas formadas por um número menor de alunos facilitem o processo da formação dos conceitos e promovam também uma interação mais participativa.

A horta escolar foi considerada como um espaço educador, pois o ensino foi organizado de maneira a possibilitar a formação de conceitos científicos e pesquisa na escola, além da inserção, de forma interdisciplinar, dos temas transversais. O ambiente da horta simulou uma vivência real que contribuiu para a relação dos alunos com o espaço da escola e do entorno, rompendo com o ensino considerado tradicional, numa nova perspectiva metodológica.

O processo dinâmico da formação dos novos conceitos e os diferentes níveis de formação conceitual dos alunos exigem um olhar para o processo e destacam que a avaliação da aprendizagem também deve estar direcionada para o processo e não somente para a etapa final, pois os conceitos não podem ser formados somente com uma única explicação inicial. A Teoria Histórico-Cultural contribui para que uma análise processual aconteça na escola.

As contribuições da pesquisa para estudos futuros apontam para o processo da formação do pensamento teórico dos alunos e a construção do currículo na escola com conceitos inter-relacionados, visando à continuidade do processo da formação de conceitos científicos.

Além disso, a organização do ensino tendo o aluno como núcleo desse processo pode proporcionar o desenvolvimento das funções psicológicas complexas, que colaboram com a aprendizagem. Vários processos do desenvolvimento das crianças são necessários para que um conceito seja formado, mas o papel ativo do processo educativo revelou-se nas relações entre os alunos, professores e a comunidade escolar, nos espaços da escola, do bairro e da horta, contribuindo para a formação de novos conceitos. Assim sendo, esses fatores devem ser considerados para o estudo e a produção de atividades de aprendizagem na perspectiva histórico-cultural.

\section{Referências}

BRASIL. Ministério da Educação. Base nacional comum curricular. Brasília: MEC, 2018. Disponível em: http://basenacionalcomum.mec.gov.br/. Acesso em: 10 jul. 2019. 
BRASIL. Ministério da Educação. Diretrizes curriculares nacionais para a educação ambiental. In: BRASIL. Ministério da Educação. Diretrizes curriculares nacionais gerais da educação básica. Brasília: MEC, 2013. p. 515-542. Disponível em: http://tinyurl.com.br/2la. Acesso em: 5 fev. 2018.

CAMPOS, M. C. C.; NIGRO, R. G. Teoria e prática em ciências na escola: o ensino-aprendizagem como investigação. São Paulo: FTD, 2009.

CAVALCANTI, L. S. Geografia, escola e construção de conhecimentos. Campinas: Papirus, 1998.

CAVALCANTI, L. S. A geografia escolar e a cidade: ensaios sobre o ensino de geografia para a vida urbana cotidiana. Campinas: Papirus, 2008.

GÓES, M. C. R. A abordagem microgenética na matriz histórico-cultural: uma perspectiva para o estudo da constituição da subjetividade. Cadernos Cedes, Campinas, v. 20, n. 50, p. 9-25, 2000. DOI: http://doi.org/ds8mgj.

GONZÁLEZ, A. G. G. Bases conceituais da teoria histórico-cultural: implicações nas práticas pedagógicas. 2012. 190 f. Dissertação (Mestrado em Educação) - Centro de Educação e Ciências Humanas, Universidade Federal de São Carlos, São Carlos, 2012.

LOUREIRO, C. F. B. Educação ambiental transformadora. In: LAYRARGUES, P. P. (coord.). Identidades da educação ambiental brasileira. Brasília: Ministério do Meio Ambiente, 2004. p. 65-84.

LURIA, A. R. Vigotskii. In: VIGOTSKII, L. S.; LURIA, A. R.; LEONTIEV, A. N. Linguagem, desenvolvimento e aprendizagem. 14 ed. São Paulo: Ícone, 2016. p. 21-38.

MEIRA, L. Análise microgenética e videografia: ferramentas de pesquisa em psicologia cognitiva. Temas em Psicologia, Ribeirão Preto, v. 2, n. 3, dez. 1994. Disponível em: http://tinyurl.com.br/2lb. Acesso em 18 jun. 2017.

MOLON, S. I. Subjetividade e constituição do sujeito em Vygotsky. Petrópolis: Vozes, 2016.

PRIMAVESI, A. Cartilha do solo. São Paulo: Fundação Mokiti Okada, 2006.

VIGOTSKI, L. S. A formação social da mente: o desenvolvimento dos processos psicológicos superiores. 7. ed. São Paulo: Martins Fontes, 2007.

VIGOTSKI, L. S. Pensamento e linguagem. 4. ed. São Paulo: Martins Fontes, 2008.

VIGOTSKI, L. S. A construção do pensamento e da linguagem. 2. ed. São Paulo: WMF Martins Fontes, 2009.

VIGOTSKI, L. S. Psicologia pedagógica. 3. ed. São Paulo: WMF Martins Fontes, 2010. 